\title{
LOS GUSTOS DE LA AUDIENCIA INFANTIL Y LA PRODUCCIÓN TELEVISIVA \\ El conflicto pragmático de los responsables de la audiencia infantil
}

\author{
Luis Núñez Ladevéze \\ Universidad San Pablo-CEU \\ José Ramón Pérez Ornia \\ Universidad Complutense
}

\begin{abstract}
RESUMEN
Este artículo se basa en el comentario de varias encuestas realizadas por el Centro de Investigaciones Sociológicas sobre hábitos televisivos, especialmente la realizada en el mes de mayo del año 2000 sobre "La televisión y los niños: hábitos y comportamientos», de mil ochocientas entrevistas. En ella se recoge importante información sobre la conducta efectiva de los niños y sobre la relación entre los padres (o tutores, en su caso) y los hijos menores y adolescentes en lo relativo a la televisión. El comentario no se enfoca a investigar la actividad de la audiencia con relación al consumo televisivo, trabajo que ya se ha realizado también bajo patrocinio del CIS, sino a formular algunas hipótesis sobre el sentido de ciertos datos estadísticos relevantes.
\end{abstract}

\section{EL MEDIO DE COMUNICACIÓN Y SU USO}

\section{Introducción}

De qué modo influye la televisión en nuestra sociedad y hasta qué punto en la formación social del niño es asunto que se viene discutiendo desde hace tiempo tanto en el nivel reflexivo de las grandes palabras y teorizaciones globales como en el de la sociología empírica.

Con relación a los intentos de interpretaciones comprensivas del fenómeno de la televisión desde una perspectiva global se pueden distinguir dos actitudes opuestas, aunque sus niveles de contraste pueden graduarse, cuyos extremos 
podrían quedar representados por las reflexiones de McLuhan ${ }^{1}$, por un lado, y el ensayo de Sartori Homo videns, por otro ${ }^{2}$.

En cuanto a la sociología empírica, ningún estudio puede considerarse concluyente bajo ningún aspecto. La acumulación de material es inmensa y las aportaciones tan variables y dispersas como las perspectivas y los enfoques.

Este trabajo va a limitarse a un comentario de datos de la última encuesta realizada por el CIS sobre «La televisión y los niños: hábitos y comportamientos» ${ }^{4}$. Tendremos en cuenta también algunos aspectos complementarios considerados en otros estudios anteriores ${ }^{5}$ y, en especial, dos estudios, uno sobre "Hábitos de comportamiento ante la televisión" y otro sobre "Tecnologías de la información y la comunicación» ${ }^{7}$. Se harán también referencias al proyecto

${ }_{1}^{1}$ M. McLuhan, The Gutenberg Galaxy, Univ. Toronto Press, 1962 (ed. española de Círculo de Lectores, La galaxia Gutenberg, Barcelona, 1998, por la que citamos).

${ }^{2}$ G. Sartori, Homo videns, Roma, Gius, Laterza \& Figli Spa, 1997 (ed. española: Madrid, Taurus, 1998, por la que citaremos). No hay ninguna alusión o referencia que permita pensar que el ensayo de Sartori sea una respuesta a la obra de McLuhan, excepto el mismo título, que contrapone el homo videns al homo typographicus. Las referencias a McLuhan y a la noción de «aldea global» son laudatorias más que críticas, aunque luego disiente en la consideración de la función que corresponde a la televisión en la "globalización» (pp. 117 y ss.).

De los numerosos comentarios sobre la nocividad de la dependencia televisual del niño, probablemente ha sido la crítica del ya fallecido filósofo Karl Popper la que ha suscitado más debate. Cfr. K. R. Popper y J. Condry, La televisión es mala maestra, Madrid, FCE, 1994.

${ }^{3}$ A modo de ejemplo, B. Hodge y D. Tripp, Childrens and Television, Oxford, Basil Blackwel, 3. ${ }^{a}$ reimp., 1994; G. L. Berry y J. K. Asamen, Children \& Television, London, Sage, 1993. Véase bibliografía citada en ambos.

Destacan, asimismo, las publicaciones de The Unesco International Clearinghouse on Children and Violence on the Screen, incluida su revista ICCVOS, publicada por la Universidad de Göteborg (Suecia), y las del Centro Reina Sofía para el Estudio de la Violencia. Cfr. L. Núñez Ladevéze, "Ética de los contenidos televisivos y mecanismos para su análisis», en Ética y Televisión, Valencia. En España tuvo en su momento importancia Alonso Erausquin, Matilla y Vázquez, Los teleniños, Barcelona, Laia, 2. ${ }^{\text {e }}$ ed., 1986.

Más comprensivo: J. Ferrés, Televisión y educación, Barcelona, Paidós, 1.a reimp., 1995.

${ }^{4}$ Estudio 2391, mayo de 2000. La encuesta es de ámbito nacional, con exclusión de Ceuta y Melilla, para un universo de población española entre 7 y 16 años, mediante 1.787 entrevistas realizadas en 227 municipios. Mientras no se haga constar expresamente, los cuadros intercalados en el texto remiten a este estudio 2391.

5 Estudio 2238, febrero de 1997. Ámbito nacional, incluidas provincias insulares y excluidas Ceuta y Melilla; 2.500 entrevistas de población española de 18 años o más, afijación proporcional, 163 municipios y 44 provincias en puntos de muestreo polietápico, estratificado por conglomerados, con selección aleatoria proporcional, rutas aleatorias y cuotas de sexo y edad.

6 Estudio 2272, «Hábitos de comportamiento ante la televisión», enero de 1998. Encuesta de 400 entrevistas en 57 secciones del municipio de Madrid a población entre 6 y 18 años, aplicándose un cuestionario complementario a la madre o padre o tutor. Coeficientes de ponderación por tramos de edad. Bietápico, estratificado por conglomerados, selección aleatoria y proporcional y rutas aleatorias por cuotas de sexo y edad.

7 Estudio 2292, "Tecnologías de la información y la comunicación», junio de 1998. Ámbito nacional para población de 15 años y más en 139 municipios y 43 provincias, incluidas insulares y excluidas Ceuta y Melilla. Afijación no proporcional. Coeficientes de ponderación. Muestreo polietápico, estratificado por conglomerados, con selección aleatoria proporcional de unidades primarias y secundarias, rutas aleatorias y cuotas de sexo y edad. 
de investigación perteneciente al Programa Sectorial de Promoción del Conocimiento, que los propios autores de este artículo realizan bajo el título de «Estudio de la oferta y de las preferencias temáticas de la audiencia televisual infantil en España» ${ }^{8}$. Conviene dejar constancia de que la encuesta del CIS fue diseñada a propuesta y con la colaboración de los autores de este comentario para disponer de material sociológico complementario de los análisis de audiencia y de contenido en los que principalmente se basa el proyecto de investigación citado, y cuyo objetivo principal es determinar la composición de la audiencia infantil según las distintas franjas horarias y estudiar el contenido de los programas que los niños efectivamente ven.

Lo que tiene especial interés de ese proyecto de investigación, en estos momentos in fieri, es que permitirá comparar y confrontar los juicios de valor de los padres y tutores de los niños — personas a quienes la sociedad tácitamente y las normas estatales de modo expreso confían su cuidado y sobre las cuales descarga la responsabilidad de educar la conciencia infantilsobre cómo ha de ser una conducta responsable del tutor con su conducta efectiva. En suma, cómo creen que deben enseñar al niño a ver la televisión y cómo realmente le enseñan. Hay, pues, tres niveles de análisis que es necesario separar y confrontar. Por un lado, los juicios de valor de padres y tutores (se prescinde de los educadores profesionales, pero podría pensarse en un futuro estudio complementario que abordase ese particular). En segundo lugar, la conducta práctica de los responsables con relación a la audiencia infantil de televisión, es decir, en qué medida el comportamiento de los implicados en la formación y la vigilancia de los niños y la atención que prestan a lo que los niños ven por televisión refleja o desmiente sus propios juicios de valor como responsables de su cuidado. En la medida en que los desmienten, puede hablarse de un conflicto entre juicios y conductas, o sea, de una «disonancia pragmática» entre el pensamiento y la acción. Identificar y aportar algunas ideas sobre la magnitud y el sentido de ese hipotético conflicto pragmático constituye el núcleo principal de nuestra investigación. En tercer lugar, la conducta efectiva de los niños en contraste con lo que los responsables de su cuidado afirman que debe ser, es decir, lo que piensan los tutores que pueden o no pueden ver los niños, y a qué horas, en comparación con lo que realmente los niños ven. Se trata de un aspecto complementario de la paradoja pragmática mencionada.

Se pretende que el comentario de los datos se integre en una perspectiva teórica, de modo que el análisis sirva para aportar distinciones que puedan utilizarse para validar o reformar conceptos abstractos en el marco de la discusión teórica global. Para simplificar, hemos adoptado como punto de referencia para la confirmación o refutación de hipótesis teóricas abstractas los planteamientos de McLuhan y Sartori. Consideramos que sus puntos de vista afron-

${ }^{8}$ Se trata de un subproyecto de investigación que forma parte de un proyecto coordinado titulado «La televisión y los niños. Programación infantil y anomia televisiva». 
tan la perspectiva más amplia desde la que se puede tratar el análisis empírico de la televisión ${ }^{9}$.

Algo puede decirse, para empezar el comentario. En el comienzo del nuevo siglo la ecología del niño ha cambiado sustantivamente. No solo incluye "computadoras y videojuegos, discos digitales», como observaba Murray ${ }^{10}$, sino que a estas herramientas materiales hay que añadir también Internet. El niño encuentra en el hiperespacio virtual algo más que un instrumento material, todo un entorno relacional y múltiple abierto a su imaginación. Los procesos de cambio no han hecho más que empezar, pero se puede conjeturar fácilmente el sentido de su progresión.

La consideración de las encuestas realizadas en el intervalo de dos años indica, aunque todavía sea incipiente y los términos no sean directamente comparables, ese cambio que se está produciendo a ojos vistas ${ }^{11}$.

La encuesta de enero de 1998 describe hábitos de comportamiento ante el televisor en la Comunidad de Madrid. En ella el 91,1\% manifestaba disponer

9 Al presentar graduable la contraposición entre ambas actitudes pretendemos salirnos de la disyuntiva preconfigurada por ECO de «apocalípticos», por un lado, e «integrados», por otro.

${ }^{10}$ J. P. Murray, "The Developing Child in a Multimedia Society», en Children \& Television..., pp. 9-23.

${ }^{11}$ Aunque la acumulación del material empírico es muy amplia, como de lo que se trata es de estudiar preferencias y comportamientos electivos, prescindimos de antemano de cuanto se refiera a situaciones en que la oferta televisiva no es comparable con la actual, que abarca no sólo las cadenas autonómicas y privadas, sino también las televisiones de pago. A estos efectos, un estudio cualitativo tan interesante como el de Javier Callejo Gallego, La audiencia activa. El consumo televisivo: discursos y estrategias, publicado por el CIS (Madrid, 1995), resulta envejecido para los datos que requieren nuestras pretensiones. La posibilidad de comparar los juicios establecidos en dicho trabajo con los resultados de la investigación que proponemos, expresamente orientada al estudio cuantitativo de la audiencia, queda, por otro lado, fuera de nuestros propósitos en este artículo, que se refieren, concretamente, a consignar la disonancia pragmática entre juicios y conductas, asunto que, por lo que a nuestro conocimiento alcanza, tanto empírica como conceptualmente, carece de precedentes expresos. La obra de Callejo se propone estudiar lo que los individuos buscan en la televisión y cómo las «formas de consumo" del medio televisivo se expresan en la estructura social. Aunque no lo parezca, este método, sustantivamente válido y sociológicamente innovador en muchos aspectos, no afecta prácticamente a las relaciones comerciales entre empresas, productores televisivos y receptores. De hecho, el incidir en y mostrar que la audiencia no es uniforme sino plural, y en que los usos de la televisión no son coincidentes aun para los destinatarios que atienden a un mismo contenido programado, refuerza las actitudes de los promotores del mercado, es decir, de los empresarios y productores: que el destinatario sepa lo que ve y por qué lo ve, lo constituye en última instancia en el responsable de lo que se le ofrece. Poco importa al mercado si los usuarios ven o no ven de la misma manera los mismos o diferentes programas cuanto que la mayor parte posible vea el contenido que el empresario programa y por el que compite (cfr. op. cit., p. 252). Ni que «no todos los componentes de la sociedad vean de la misma manera la televisión» (íd., 256) mientras el mayor número vea lo mismo durante el mayor tiempo posible. Es decir, desde este punto de vista, no importa tanto lo que «buscan» en la televisión ni por qué lo buscan los destinatarios cuanto lo que «encuentran» por el hecho de buscar de una u otra manera. Y lo que encuentran como contenido, que es el objeto de este comentario, puede describirse como el denominador común audimétricamente cuantificable de la variedad de búsquedas efectivas. En términos lingüísticos estructurales, podría definirse como «la invariante encontrada de las distintas variantes búsqueda». 
de vídeo. En junio de 1998 un 26,3\% decía que utilizaba el ordenador personal, un $10,9 \%$ antena parabólica y un $7 \%$ decía estar abonado a alguna plataforma digital. En la encuesta nacional de mayo de 2000 el 90,3\% declara disponer de vídeo, 11,2\% estar abonado a alguna plataforma digital, un 16\% posee Canal + y un 5,5\% televisión por cable. Declara tener ordenador el $43,9 \%$ de los encuestados. Aunque las cifras no sean homologables por no tratarse de cuestionarios correlativos, el sentido de la proyección sobre el aumento de abonos a plataformas digitales y, en especial, sobre el uso del ordenador sí es significativo.

\section{El entorno conceptual}

Desde el punto de vista teórico, es importante establecer algunas distinciones previas para acotar el enfoque en que se enmarca nuestro comentario (y que está directamente relacionado con el proyecto de investigación antes mencionado). Se entiende la televisión como un tipo de «medio de comunicación social». Pero la expresión «medio de comunicación» — como toda otra- es usada de un modo tan polivalente que muchas veces designa cosas relacionadas entre sí porque se aplica una misma palabra para designarlas, aunque sean de naturaleza distinta. En lo que es relevante para la consideración de estos trabajos, creemos que la expresión «medio de comunicación» suele usarse en ciencias sociales, semiológicas y lingüísticas para referirse a tres tipos de realidades que conviene separar. El lenguaje, dicen los lingüistas, es un medio de comunicación. También lo es el libro. Y Norbert Wiener, en Cibernética, incluye la escuela, la iglesia y la empresa entre los medios de comunicación. Pero lenguaje, libro y escuela son «medios comunicativos» de especie diferente ${ }^{12}$.

Sirviéndonos de la adaptación de Jakobson ${ }^{13}$ del proceso de comunicación, podemos convenir en que la lengua es un medio de comunicación en el sentido de código o de sistema de signos mediante los que se elabora el mensaje; el aparato de televisión, el vídeo, el cinematógrafo, lo son en el sentido de que son medios que sirven de soporte o de canal de circulación de los mensajes, y la escuela, la empresa o la iglesia en el sentido de que son entornos o contextos de interacción entre los autores de mensajes. Cuando se habla de televisión o de Internet, no haciendo referencia concreta al artilugio, nos referimos a las tres cosas a la vez. Se trata de canales o de media de comunicación, por los que circulan mensajes (medio de comunicación codificado en una lengua) que tienen influencias sociales (medio de comunicación institucional o contextual). Así que tenemos un medium (el sistema de difusión de televisión, aparatos,

${ }_{12}$ Cfr. Núñez Ladevéze, «Para un tratamiento autónomo de la noción y las funciones del medio de comunicación de masas», en REIS, n. ${ }^{\circ} 22$, 1983, pp. 101-119.

${ }_{13}$ Jakobson, "La lingüística y la poética», en Estilo del lenguaje, Th. Sebeok (rec.), Madrid, 1974. 
etc.) cuyo contenido es un medio (el lenguaje icónico y hablado principalmente) y que, a su vez, está contenido en otro medio (el sistema de interacciones sociales producido por la televisión: el sistema de interacción social sería distinto si no mediara la televisión). Algo que ya anticipó McLuhan en Comprender los medios de comunicación: el contenido de un medio de comunicación es otro medio de comunicación ${ }^{14}$.

Pues bien, cuando aquí hablamos de la televisión, nos referimos globalmente a un fenómeno que abarca un proceso de institucionalización social derivado de un uso predominante de un medium, un uso que, a nuestro entender, condiciona (o, tal vez haya que decir, determina) mensajes de contenidos específicos ${ }^{15}$. Esta descripción satisface las condiciones de McLuhan acerca de sus observaciones de que el medio es el mensaje. Es la posibilidad de uso social del medio, y no el uso particular de que es objeto, lo que interesa... "porque el "mensaje" de cualquier medio o tecnología es el cambio de escala, ritmo o patrones que introduce en los seres humanos... El medio es el mensaje porque es el medio el que modela y centra la escala y forma de las asociaciones y trabajo humanos» ${ }^{16}$. No se trata sólo del hecho de que se pueda ver a distancia a través de la pantalla —o de la propiedad de la televisión de ver a través de cuerpos opacos, como diría Gustavo Bueno- ${ }^{17}$, sino del hecho de que se pueda multiplicar un mensaje audiovisual y suministrarlo al mismo tiempo gratuita $\mathrm{u}$ onerosamente en condiciones impuestas por el mercado a una audiencia tan amplia como pueda ser posible. La consideración de este aspecto institucional del medio muestra hasta qué punto condiciona el uso del medium como canal y puede que determine la orientación de sus mensajes o contenidos. Esto es macluhanismo casi puro pero no menos puro sartorismo ${ }^{18}$. La diferen-

${ }^{14}$ «... el efecto de un medio solo se fortalece e intensifica porque se le da otro medio que le sirva de "contenido"”. M. McLuhan, Understanding Media. The Extensions of Man, Cambridge, MIT Press, 1964 (v.e.: Comprender los medios de comunicación. Las extensiones del ser humano, Barcelona, Paidós, 1996; cito por esta edición).

${ }_{15}$ No es esto lo que exactamente dice McLuhan cuando insiste en que «el medio es el mensaje», pero está implícito en su consideración de que el "contenido" carece de relevancia porque lo que importa es el medio mismo y no "cómo se utiliza». Sobre este aspecto es interesante la interpretación de Gustavo Bueno, que distingue, inspirándose de Hjelmslev, entre estructura y contenido del medio de comunicación. Cfr. G. Bueno, La televisión: apariencia y verdad, Barcelona, Gedisa, 2000.

${ }_{16}$ M. McLuhan, Understanding..., p. 30.

17 Op. cit.

18 G. Sartori, Homo videns. No obstante, el aspecto más llamativo de la confrontación entre las actitudes de McLuhan y Sartori, es decir, de quienes alaban y quienes censuran el medium televisivo en sí mismo, no considerando su uso sino su función social, radica en que, sorprendentemente (si se nos permite esta advertencia), para McLuhan la televisión no es un medio visual (como su propio nombre de "visión a distancia» indica), sino táctil: «la televisión es, sobre todo, una extensión del sentido del tacto que implica una mayor interacción entre todos lo sentidos» (íd., 338); mientras que para Sartori (siguiendo una línea de interpretación al menos aparentemente menos caprichosa) es un medio audiovisual cuyo peligro consiste en que puede sustituir la capacidad abstracta del lenguaje, que la escritura y la lectura potencian, por el lenguaje concreto y menos elaborado de imágenes o icónico, lo que, a su juicio, supondría una regresión: 
cia entre Sartori y McLuhan en este aspecto se refiere al juicio de valor y a los pronósticos, es decir, a las consideraciones que cada uno establece sobre el particular y a los efectos que conjeturan con respecto a lo que el medio impone como sistema (o en el proceso) de institucionalización social. Mientras que para McLuhan la televisión genera una nueva y más creativa relación entre los sentidos y los mensajes, para Sartori la televisión sustituye la capacidad analítica y reflexiva implícita en el lenguaje abstracto escrito por una dependencia icónica de las facultades intelectivas y reflexivas que puede conducir a su atrofia. Empleamos los términos «macluhanismo» y "sartorismo» como tipos ideales puros de actitudes confrontables acerca de la influencia social de la televisión. Aunque sus actitudes sean antitéticas, coinciden en el aspecto fundamental de que ambos centran su atención en el medio mismo y en su institucionalización social (es decir, en los sentidos segundo y tercero que antes distinguimos relativos a la expresión «medio de comunicación»), más que en los contenidos que puede difundir o transmitir, respecto de los cuales el lenguaje es un medio de comunicación (primer sentido).

Veamos una importante consecuencia teórica relacionada con esta diferencia conceptual y referencial de la expresión «medio de comunicación». Tanto para McLuhan como para Sartori, es inútil plantearse como problema el contenido de los medios de comunicación porque «el medio es el mensaje» en el sentido de que son los mensajes los que se adaptan a la potencialidad social del medio televisivo. Por "potencialidad social» puede entenderse algo como lo siguiente: puesto que el regulador social de los contenidos del medio es la audiencia, a largo plazo será la satisfacción de los gustos de la audiencia la que determinará los contenidos televisivos ${ }^{19}$. De aquí que sea estéril la crítica de si los programas y los contenidos de la televisión son o no gregarizadores, triviales, antiestéticos o vulgares. Coincide Sartori con McLuhan en considerar que el medio determina el mensaje, pero su diagnóstico es justamente el contrario. En lugar de facilitar la comunicación en "la aldea global», la televisión, en cuanto forma culturalmente dominante de comunicación, pone en peligro la capacidad de razonamiento abstracto al implantar socialmente un pensamiento icónico (?) basado en la continuidad de imágenes, es inevitablemente intelectual y culturalmente degradante. Nuestro interés no será optar por uno u otro ni mantener equidistancia, sino tenerlos en cuenta para que se comprenda el entorno global de apreciaciones críticas en que puede ubicarse el comentario sobre los efectos de la televisión (y más concretamente en la audiencia infantil) ${ }^{20}$.

«el telespectador es más un animal vidente que un animal simbólico» (p. 26). Pero lo que interesa es que no importa el contenido que se vea sino el hecho social de que se sustituye la abstracción lingüística (ligada a la escritura) por la sensación visual.

${ }_{19}$ Coincide en este punto de vista Derrida. Cfr. J. Derrida y B. Stiegler, Ecografias de la televisión. Entrevistas filmadas, Buenos Aires, Eudeba, 1998.

${ }^{20}$ Se trata de concebirlas como «tipos ideales» y no como una mera disyuntiva culturalista. Creemos que este modo de considerarlas, con las reservas que se quieran adoptar acerca de su idoneidad, no deja de ser una aportación metodológica. 


\section{Los usos sociales del medio televisivo}

Hasta la aparición del vídeo, el uso social de la televisión en España (en el sentido antes expuesto y que especificaremos algo más) era uniforme. Vista institucionalmente, el efecto predominante consistió en su progresiva implantación como artilugio doméstico habitual en la vida cotidiana de la población y en la difusión de un entorno cultural de referencias comunes. Ese uso se caracterizaba por la venta de una audiencia indistinta por parte de los empresarios y programadores a los publicitarios. La ampliación de la oferta televisual con la aparición de las televisiones autonómicas y privadas no modifica el entorno, sino que agudiza sus posibilidades. La pugna entre las televisiones llamadas "generalistas» por ampliar audiencia no contribuye a diversificar la oferta de la programación. La competencia entre televisiones gratuitas públicas o privadas de difusión general (o de difusión comunitaria, pues su destinatario es sólo una parte de esa misma población en disputa con las generales) no actúa como un factor de diferenciación de los programas. Eso se advierte no sólo por el hecho de que exista un mercado internacional de contenidos de televisión al que concurren empresas de las más diversas procedencias culturales, o por la facilidad con que se traducen los programas de una lengua a otra, sino también por otros fenómenos que se han estudiado como el de la contraprogramación o el mimetismo de las cadenas. Bien es cierto que la competencia ha favorecido la aparición y rápida consolidación de una industria nacional de producción de programas que ha frenado la dependencia del mercado estadounidense, sobre todo en los géneros de la ficción y en otros formatos del entretenimiento televisivo, productos todos ellos estratégicos en las rejillas de programación de todas las cadenas generalistas. Lo que tiene interés es el éxito del programa y la experiencia comercial muestra que, en principio, si un programa tiene éxito en un entorno, pronto se probará si lo tiene en otro o habrá un imitador que trate de repetirlo. Por "éxito" no se entiende otra cosa distinta de rentabilidad comercial y, por tanto, de acumulación de audiencia a efectos publicitarios.

Por otro lado, como todas las cadenas pretenden la adhesión del mayor número posible de telespectadores, los contenidos tratan de adaptarse a los gustos o tendencias más ampliamente compartidos, al denominador común que subyace a las diferencias de interés, capacidad de apreciación estética y conocimiento $^{21}$. Incluso aunque se utilice el medio como un instrumento para la promoción de aspectos de la identidad colectiva (por ejemplo, lingüística o cultural), la pretensión de adquirir o retener audiencia que puede ser capturada por la competencia actúa de modo que el estilo y la orientación de los contenidos de la programación se mantengan uniformes. Todos los programas en su

21 «Las cosas se dirigen siempre por la dirección que presenta menor resistencia. En otras palabras, se va siempre por la parte que resulta más fácil, aquella en que uno se ayuda a superar un problema, reduciendo las obligaciones del trabajo». Popper, op. cit., p. 47. Cfr. L. Núñez Ladevéze, Ideología y libertad, Madrid, Noesis, pp. 219-225. 
diversidad presentan un mismo tono familiar. Las mismas series, los mismos protagonistas, similares tertulias o los mismos partidos se pueden ver en lenguas distintas, formando una epidermis de ambiente común sobre los sustratos de las más diferentes culturas y por encima de las diferencias de los más diversos estratos sociales. Ese condicionamiento uniformizador resulta encauzado por el hecho de que los programas tienden a compartir la misma pretensión de servirse del medio para un mismo fin: el de apoderarse de la audiencia ajena y retenerla ofreciéndole los contenidos que el medio permite difundir. En eso consiste el aspecto principal del condicionamiento del mensaje por el uso social del medio 22 .

Sin embargo, de la propia renovación tecnológica comienzan a manifestarse los indicios de que surgen nuevas tendencias que se orientan más a la fragmentación que a la uniformidad. La difusión del vídeo constituye un primer factor de diversidad. El telespectador ya no queda supeditado a elegir entre la variedad de una programación que busca fijarlo en competencia con otras. Después, con la televisión de pago y el cable, la uniformidad se fragmenta. Ahora estamos introduciéndonos en un entorno diferente como consecuencia de la propia evolución técnica del medio. Siguiendo con esta perspectiva macluhiana que considera al medio como un contenido del medio cuyas extensiones proyectan los cambios de entorno, cabe pensar que se produzca un cambio de adaptación a las nuevas tecnologías de la era eléctrica, entre las que se cuenta ahora Internet.

Sin duda, pero antes hay que hacer algunas precisiones sobre el sentido en que estamos hablando de la televisión como medio de comunicación y de interacción social. Cuando hablamos de la televisión como mero medio, nos referimos a los posibles usos de un instrumento. Esos usos determinan tipos de mensajes distintos. No es lo mismo que la televisión se use para fines didácticos o como medio de exploración científica (piénsese en el uso quirúrgico de la telecámara) que como medio de oferta generalizada o de entretenimiento social. ¿Qué diferencia hay entre una y otra cosa? En el primer caso, la televisión es instrumento de un fin y de un contenido a cuyo servicio se dedica el medio. Por decirlo de otra manera, el medio es instrumento de un mensaje preexistente. No cambia el mensaje didáctico, sino el modo de enseñar ese mensaje. El contenido didáctico no ha de adaptarse a una audiencia, ni es regulado por ni entra en interacción con ella. Tampoco cambia el órgano que la telecámara explora, sino que el instrumento explora ese órgano para comprobar si está sano o enfermo o mostrar al cirujano dónde debe extirpar. En el

22 La «uniformidad» de los contenidos es un efecto de la relación programación-audiencia que es independiente del hecho de que la audiencia sea «activa», pues lo que el programador busca en las televisiones "generalistas" que compiten por la audiencia es acertar con el denominador común de las distintas actitudes y satisfacerlas: la adaptación al denominador común de los gustos, sean cuales sean los motivos por los que los distintos tipos de telespectadores acaban convirtiéndose en audiencia uniforme. Este asunto no ha sido ponderado por Javier Callejo en su investigación sobre «las estrategias de la audiencia activa». 
segundo caso, lo que cambia es la relación entre mensaje y audiencia. Éste se adapta a aquélla, o viceversa.

Por tanto, ¿bajo qué alcance o perspectiva hemos de considerar la función del medio? En un caso el medio no crea funciones nuevas, satisface funciones preexistentes de manera distinta. El que se usen cámaras de televisión para operaciones quirúrgicas no modifica más que la efectividad de la cirugía, cambia la técnica, la eficacia, pero no altera la función quirúrgica. No se modifica la función de la cirugía, sino los procedimientos de que se vale el cirujano. Pero cuando se pone la televisión (segundo sentido de medio de comunicación) al servicio de los gustos de una audiencia y no de un fin específico previo, de modo que es la audiencia la que regula el contenido y por ello la finalidad, entonces la televisión no sólo tiene un valor instrumental específico, como medium o canal (segundo concepto de medio de comunicación), sino un valor social que expresa gustos sociales y cuya función está directamente regulada por procesos de interacción mercantil, de oferta y demanda. Es desde ese punto de vista que puede decirse que la televisión, socialmente considerada (tercer sentido de televisión como medio de comunicación), es, ante todo, un medio social principalmente orientado a satisfacer necesidades de entretenimiento. Lo es porque así lo quiere la sociedad, así lo decide la audiencia. En sentido "macluhiano», puede decirse entonces que la televisión no sólo es un instrumento que modifica las formas de entretenerse, sino una forma nueva de entretenerse que antes no existía y que puede convertirse, y de hecho en eso se convierte, en el medio de otros medios de entretenerse, a los que sustituye o que modifica al superponerse a ellos ${ }^{23}$.

Trataremos ahora algunos de los aspectos relativos al cambio que se está produciendo por la aparición de otros medios de comunicación - extensiones de los sentidos socialmente configurados-, bien por desarrollo tecnológico de la propia televisión, o bien distintos de y competitivos con ella, basándonos en los datos proporcionados por las encuestas enumeradas al comienzo de este trabajo. Puntualizamos que se trata de encuestas recientes y que se refieren a un escenario uniforme sobre la estructura cambiante de la televisión comercial, pues no es posible comparar situaciones en que las cadenas de televisión privada no están plenamente socializadas con situaciones en que, además de estarlo, tienen que competir con la penetración doméstica de Internet y la oferta televisiva temática y por satélite. Aunque los datos entre encuestas no sean exactamente homogéneos, sí pueden ser significativas algunas de las indicaciones.

En la encuesta de junio de 1998 sobre «Tecnologías de la información y la

${ }^{23}$ El uso didáctico o científico de la televisión es, desde este punto de vista, secundario. No responde a las condiciones que hemos establecido de niveles de "medio de comunicación» como instrumento de difusión de mensajes y de institucionalización social. Usada de esa manera, la televisión es un medio complementario, no sustantivo. Pero entendida la televisión como medio de institucionalización social, ocurre al revés. Justamente cuando se estudian los hábitos televisivos se hace referencia a ese uso y a ese tipo de proceso. 
comunicación", casi el $60 \%$ de los entrevistados $(57,9 \%)$ responde que tiene en su casa más de un televisor, y más del setenta que tiene vídeo. Es decir, en 1998 había más familias españolas que tienen al menos dos televisores que familias españolas que tienen microondas (46\%), lavavajillas $(24,8 \%)$ o equipo de música $(52,1 \%)$. En la encuesta de enero de 1998 el promedio de televisores es de 2,02, y en la de 2000 la media de aparatos es de 2,13 por hogar.

En la última encuesta del CIS hemos visto cómo todavía la televisión es predominante con relación a esos otros medios, pero también que estamos en una zona de tránsito cuyas variaciones e influencias son difíciles de prever, porque se fragmenta el sentido uniforme de la institucionalización social de la dependencia televisiva.

En todo caso, ateniéndonos a los datos actuales, parece claro que, por mucho que se insista en la dependencia social de la producción televisiva, será difícil incurrir en exageraciones. No se trata sólo de la audiencia o del volumen de la cifra de negocios, ni tampoco de la importancia creciente de nuevos métodos y canales de difusión. Lo que importa, a nuestros efectos, es que la rivalidad por ganar audiencia es la causa principal de esa dependencia social respecto de la televisión cuyos efectos son equívocos. Porque si, por un lado, no cabe duda de que ha contribuido a aumentar la oferta, a reforzar la industria audiovisual y a vitalizar la producción, por otro, se trata de una oferta tan homogénea y anodina que ofrece pocas variaciones. Los programas son miméticos, sus fórmulas se repiten como si fueran variaciones de un único patrón, las series se copian unas a otras, los concursos son espectáculos amorfos y reiterativos a partir de las fórmulas de éxito, precisamente porque programadores y productores tienden a huir del riesgo que supone enfrentarse a productos nuevos, innovadores o inéditos y porque el índice de fracaso de los estrenos es muy alto, tanto en Estados Unidos como en Europa. El triunfo de esa variedad televisiva que podría denominarse "prefabricación de la realidad" o "prefabricación del éxito", cuyos máximos exponentes fueron Gran Hermano y Operación Triunfo, ha sido, según indican los comentaristas de las preferencias de la audiencia, la gran innovación de las últimas temporadas. Es, como se ha dicho, un fenómeno sociológico. Pero, al contrario de lo que los promotores de los programas sugieren, no es tras la pantalla del televisor donde se produce el espectáculo ni es, sociológicamente hablando, el fenómeno que hay que analizar, sino ante ella. Lo que hay que investigar es por qué programas de esa especie pueden atraer intensivamente la curiosidad de tanta gente al mismo tiempo. Los productores y programadores parecen conocer bien, por intuición y hábito, esas actitudes que caracterizan a lo que llaman «público objetivo de la televisión». Si fuéramos sartorianos, diríamos que lo que el fenómeno revela es la confirmación de su tesis ${ }^{24}$.

${ }^{24}$ Es aquí donde cabe aplicar estudios cualitativos de "grupo", de los que es pionero en España el trabajo de Javier Callejo La audiencia activa, ya citado. Nuestro objeto es, no obstante, el análisis de la audiencia a través de las encuestas. No tanto lo que busca el espectador al ver la 
Como consecuencia de la importancia mercantil y de la amplitud social del fenómeno televisivo ha aumentado considerablemente el interés por conocer los hábitos de consumo y de conducta de las audiencias. Los estudios e informes de los institutos especializados que han surgido para satisfacer ese interés tienen por función principal servir de fuente de orientación a las distintas empresas difusoras y productoras. El análisis de la audiencia tiene sentido, en efecto, si se establecen series temporales cuantitativas y comparativas en relación con los programas y sus horas de emisión, o, dentro de cada programa, por las variaciones que puedan precisarse con relación a las alteraciones de contenido.

En general, puede decirse que el planteamiento de estos informes periódicos es producto de una actitud positivista. Por "positivismo» se entiende aquí algo bastante elemental: que se acepta como único criterio de calidad o de idealidad la propia respuesta de la audiencia, como si el hecho de ver un programa fuera sinónimo de gusto, de aceptación, de identificación o incluyera un juicio de valor pertinente. En realidad, ése es un modo muy particularmente acrítico de satisfacer los intereses de la propia industria, de complacerse en la simple identificación entre estética y eficacia, o de pretender elevar la eficacia, medida en conexión de audiencia, en la única o la principal razón de una industria tan poderosa e influyente como es la de la producción y la programación televisivas. También es verdad que no siempre es así y que cuando un productor o un operador se aparta de esas rutinas para probar productos innovadores, en caso de éxito obtiene réditos enormes y arrolladores porque sintoniza con una demanda latente del público, que también espera ofertas alternativas a los estereotipos dominantes ${ }^{25}$.

La elaboración de datos que utilizan esos gabinetes de investigación, como el de GECA, basados principalmente en Sofres, es imprescindible para los trabajos de investigación académica, y a partir de ella ha de orientarse a otros fines menos instrumentales. Nuestra investigación, a la que hemos aludido al comienzo de esta exposición y que forma parte de un proyecto coordinado, se propone como objetivo conocer los horarios, preferencias y las motivaciones de la audiencia infantil a la hora de decidir ver uno u otro programa o de elegir entre los de la oferta disponible. La finalidad de este trabajo se inspira en las recomendaciones del Libro verde sobre protección de los menores frente a "contenidos perjudiciales para su desarrollo", presentado por la Comisión de las Comunidades Europeas en octubre de $1996^{26}$.

televisión ni las distintas formas de ver, sino por qué estrategias distintas que expresan actitudes sociales diferentes coinciden, no obstante, en ver las mismas cosas aunque las juzguen de distinto modo. El interés del mercado es que se vea, y se desentiende de los motivos que induzcan a ver, el cual es un interés sociológico. Y no deja de ser sociológica la indagación de por qué se tiende a ver lo mismo y qué es lo que de hecho se ve.

${ }^{25}$ Como ocurrió con Operación Triunfo, que es, desde el punto de vista del contenido, una nueva variación de formato y de contenido semántico, y con Cuéntame o con Betty la fea, que son repeticiones de formatos que algunos ya consideraban desgastados. Es interesante para hacer ver hasta qué punto los programadores y los guionistas son muchas veces víctimas de sus propios prejuicios y complejos acerca de los gustos de la audiencia.

${ }_{26}$ Libro verde sobre la protección de los menores y de la dignidad humana en los nuevos servicios audiovisuales y de información, Comisión de las Comunidades Europeas, noviembre de 1996. 
En suma, los rasgos más característicos de la televisión como medio social extensivo de comunicación proceden de que la capacidad técnica del artilugio facilita que audiencias casi ilimitadas puedan sustituir, prácticamente sin coste alguno, las sensaciones que produciría la presencia efectiva en un acontecimiento accesible a muy pocos por sensaciones similares a través de la presencia virtual o mediada. Esta capacidad comunicativa, mediadora y difusora es lo que explica que se haya convertido en un instrumento cotidiano de consumo de ocio y que ése sea su uso social predominante. Cuando se habla de televisión como medio de comunicación social, es ese aspecto el que hay que tener en cuenta. Pero conviene no olvidar que, al referirnos a los contenidos, aludimos también al lenguaje como medio de comunicación. Lo que nos interesa es que, si adoptamos un enfoque "macluhiano», el contenido no es más que un medio de otro medio, y que éste es el que tiene importancia pues es el que crea modelos para nuevas teorías y nuevos públicos para aceptarlas ${ }^{27}$.

Así, pues, la capacidad difusora, la asiduidad de su uso y la comodidad sustitutiva del esfuerzo que requeriría la experiencia efectiva de las sensaciones de las que el artefacto es instrumento mediador, son los aspectos más relevantes de los efectos sociales que produce la televisión considerada como instrumento extensivo de comunicación social. En lo que sigue trataremos por separado, a través del comentario de los estudios realizados por el CIS, especialmente del 2391, «La televisión y los niños: hábitos y comportamientos», cada uno de estos aspectos $^{28}$.

\section{LA TELEVISIÓN Y LOS NIÑOS}

\section{Difusión y asiduidad}

Ocupémonos ahora, por tanto, de la difusión de la televisión como medio de entretenimiento popular, ya que éste es el uso socialmente predominante. En los últimos veinticinco años se ha producido un aumento del consumo televisivo. Antes de la aparición de la televisión privada, en 1978, el 90\% de los españoles que veían entonces la televisión le dedicaban algo más de dos horas y media. En 1990 había ascendido a tres horas y cuarto. Actualmente es aún mayor, aunque todo parece indicar que se ha estabilizado definitivamente: el español pasó durante la temporada televisiva 1999-2000 un promedio de 221 minutos diarios ante el televisor, es decir, 3 horas y 41 minutos. El con-

${ }^{27}$ Cfr. La galaxia..., pp. 206 y 260.

${ }^{28} \mathrm{La}$ encuesta se divide en dos cuestionarios. El primero, dirigido a padres/tutor, que abarca de la pregunta 1 a la 46, inclusive, se divide en cuatro partes: de la 1 a la 14 sobre asiduidad, de la 14 a la 30 sobre programas, de la 31 a la 35 sobre publicidad, y de la 36 a la 46 sobre el perfil socioeconómico y actitudinal. El segundo cuestionario se hizo a los niños y consta de tres partes correlativas con las del primer cuestionario, es decir, asiduidad, programas y publicidad. En este comentario sólo nos ocupamos de aspectos relacionados con la asiduidad y la programación. 
cepto de temporada televisiva comprende, en este caso, el período que abarca desde el 6 de septiembre de 1999 hasta el 30 de junio de 2000 y, por tanto, es coincidente e incluye el período de tiempo durante el que se realiza el trabajo de campo de la citada encuesta 2391 del CIS. Este consumo experimenta notables cambios en función de variables como la estacionalidad o la edad, factor este último al que nos referiremos más adelante.

Puede decirse que actualmente no hay hogar español que carezca de televisor. $\mathrm{Si}$ en 1975 el $90 \%$ de los hogares contaban con, al menos, un aparato, en la actualidad sólo falta en menos de un $1 \%$. Es más, la última encuesta del CIS indica que la media es de más de dos televisores por domicilio. Así lo confirman también otros institutos de investigación, como AIMC/EGM y Sofres. Según los datos de EGM referidos al año 2000, y para un universo de 34,8 millones de personas de 14 y más años, resulta que el $31,05 \%$ de esta población (10,8 millones de personas) dispone de un solo televisor; el 46,5\% (16,2 millones de individuos) tiene dos televisores, y el 21,8\% (7,6 millones de personas) tiene tres receptores de televisión. Estos datos son coincidentes con los que ofrece Sofres para el año 2000, si bien su universo se refiere a la población de 4 y más años (39,3 millones de personas): el 31,9\% (12,5 millones de personas) tiene un solo aparato de televisión, frente al 68,1\% (26,7 millones de individuos) que cuenta con dos o más televisores ${ }^{29}$. Así, pues, resulta claramente mayoritaria la presencia de más de un receptor de televisión por hogar.

Hay otro aspecto relacionado con la difusión que no conviene identificar con ésta. Se trata de la asiduidad del uso. Distinguimos, pues, entre difusión del medio y asiduidad de su uso. Lo primero tiene que ver con el patrimonio y lo segundo con el consumo. Algo puede estar muy difundido pero puede no ser muy usado. Por ejemplo, son muchos los hogares en que hay libros pero puede que sean menos los hogares en que se lean. El correo postal puede estar muy extendido pero puede ser poco usado. Posiblemente haya radio en tantos hogares como en los que hay televisiones, pero puede que la radio sea menos usada que la televisión ${ }^{30}$. La relación entre propiedad de televisores y radios y uso de televisores y radios proporciona un coeficiente o índice de consumo. Pues bien, la televisión está muy difundida y, además, su uso es tan asiduo que puede decirse que se nace con la televisión puesta. Esto significa que no es que el niño aprenda a ver la televisión, sino que el verla forma parte del proceso espontáneo de socialización. De acuerdo con los datos de la última encuesta del CIS de mayo del año 2000, el 90\% de los niños ve la televisión a partir de los cuatro años y el $97 \%$ antes de haber aprendido a leer. El 60\% de los niños ve la televisión a partir de las nueve de la noche y más de la mitad la ven solos de un modo habitual. Datos que podrían servir para reforzar una conclusión de tipo sartoriano.

29 Véanse las Memorias de AIMC/EGM y de Sofres correspondientes al año 2000.

30 El estudio 2292, de junio de 1998, sobre «tecnologías de la información», no pregunta sobre la radio. El 2238 indica que el $84,7 \%$ de los encuestados ve la televisión todos o casi todos los días, frente a un 56,5 de los que escuchan la radio, y que el 3,2\% no ve nunca o casi nunca la televisión, frente a un $26,6 \%$ que no oye nunca o casi nunca la radio. 
Ver la televisión es, pues, algo normal en la vida de aprendizaje del niño ${ }^{31}$. En realidad, lo que ve por televisión es tan normal en su vida como hablar o andar, y más que leer, ir al colegio, salir con amigos o tener juguetes. Y a través de ese hábito es como se va estableciendo el contraste entre ilusión y realidad. Hay que tener en cuenta que, según la encuesta, casi el $40 \%$ de los hogares tiene una televisión para uso del niño, y que en el $90 \%$ de esos hogares con televisor a disposición del niño, éste dispone también de mando a distancia. Es decir, que dentro de ese ambiente de habitualidad que la televisión tiene en la vida de niños y adolescentes hay que considerar que en una buena proporción la estiman como algo que, a la vez, puede ser indistintamente relacionado con la vida familiar o con la personal, un elemento del ambiente más próximo que puede quedar incorporado al espacio más ligado a las posesiones individuales o particulares del adolescente ${ }^{32}$. Comprobemos algunos datos de la encuesta relativos a la asiduidad de la televisión en la vida infantil:

\section{PREGUNTA 3}

¿A qué edad, aproximadamente, empezó su hijo a ver la televisión?

Antes de los 2 años

A partir de los 2 años

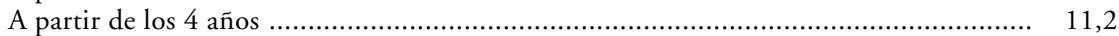

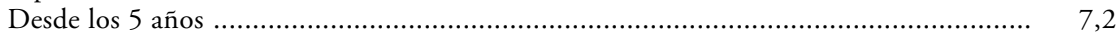

No contesta (NC)

\section{PREGUNTA 4}

¿Cuánto tiempo dedica su hijo a ver la televisión, un día laborable?

Menos de 1 hora

Entre 1 y 2 horas

Entre 2 y 3 horas

Entre 3 y 4 horas

Entre 4 y 5 horas

\section{PREGUNTA 4a}

¿Y en día festivo o perteneciente al fin de semana, incluido el viernes por la tarde?

Menos de 1 hora

Entre 1 y 2 horas

Entre 2 y 3 horas

${ }^{31}$ Cfr. Gerbner, Gross, Morgan y Signorielli, «Crecer con la televisión: proceso de aculturación», en Byrant y Zillman (eds.), Los efectos de los medios de comunicación. Investigación y teorías, Barcelona, Paidós, 1996, pp. 35-67 (ed. original: Media Effects, Advances in Theory and Research, Elbaum Assoc., 1994).

Como argumento de autoridad nos servimos, por simplificar las acotaciones bibliográficas, de los comentarios de sir Karl Popper en la obra citada.

32 Este fenómeno ya fue anticipado en el citado estudio de Callejo sobre la actividad de la audiencia. 
En suma, para el niño y el adolescente, ver la televisión forma parte tanto de la normalidad familiar como de la personal. Si ver la televisión es normal, podríamos concluir que también lo que ve es la expresión de lo nómico en el propio hogar. Aunque de esto trataremos más tarde porque para los padres supone algún tipo de conflicto práctico, paradoja pragmática, que merece examinarse más detenidamente y que constituye el objetivo final de este comentario.

Aspecto relacionado con el anterior es el de que ver la televisión está también ligado de tal modo a la noción de ocio y descanso del niño y a su entorno de gratificaciones, que los días festivos y los fines de semana aumenta el tiempo que el niño dedica a verla. Ver la televisión puede ser un premio y no verla puede ser un castigo. El 86,4\% de los niños ve la televisión porque le divierte. Si en los días de entre semana sólo un $7,7 \%$ de los niños ve la televisión entre tres y cuatro horas, y un 2,9\% entre cuatro y cinco horas, esas cifras aumentan en los días de descanso al 19,4 y al 11,2\%, respectivamente. El 40\% de los niños ve durante los fines de semana más de tres horas diarias de televisión, mientras que los días de colegio sólo lo hace el 12\%. Como es de esperar, también se prolonga el tiempo nocturno. El niño ve la televisión más tarde cuando no tiene que estudiar. Si no hay colegio, cualquier hora es buena para verla para más del $65 \%$ de los encuestados. Y si en los días laborables casi el $50 \%$ de los padres pone algún límite de tiempo para que sus hijos vean la televisión, durante las vacaciones escolares el número de los que pone límite se reduce a menos de la mitad ${ }^{33}$.

El aparato de televisión forma, pues, parte del ambiente en que se produce el proceso de socialización del niño a través de su arraigo familiar ${ }^{34}$. Eso no quiere decir que la televisión actúe necesariamente como un disgregador ${ }^{35}$. La tendencia a verla en familia, al menos un rato, es tan habitual como la contraria de verla solo (en casa), y tan frecuente para el niño como infrecuente es que la vea con amigos o con otras personas. Es decir,

${ }^{33}$ Este planteamiento va mucho más allá que el enfoque de «usos y gratificaciones», característico de un sociologismo individualista inmediatamente ligado al análisis de audiencias. Cfr. A. M. Rubin, "Usos y efectos de los medios: una perspectiva uso-gratificación», en Los efectos de los medios de comunicación. Investigación y teorías, pp. 555 y ss.

34 «Los niños aprenden a ser espectadores años antes que (sic: a ser) lectores, incluso mucho antes de aprender a hablar...", cit., p. 43.

35 «... alguien (como Leo Bogart, en 1956, en su libro The Age of Television) comenzó a observar que la incidencia de la televisión en el reforzamiento de la institución familiar podía tener como causa, no tanto la acción de los mensajes morales o las apologías de la vida doméstica destilados por los contenidos semánticos... cuanto acaso la estructura de los patrones de utilización a domicilio del aparato, en cuanto electrodoméstico; por cuanto, a diferencia de la aspiradora o del lavavajillas, al estar dotado de la capacidad de mantener reagrupados en su torno a los miembros de las familias sin necesidad de que éstos hablasen entre sí, sin perjuicio de situarlos en una fluida y eficaz comunicación no verbal, contribuía obviamente al reforzamiento de referencia». G. Bueno, op. cit., p 15. Bogart decía eso hace medio siglo, cuando sólo había un aparato de televisión por casa. Ahora el $40 \%$ de los niños tiene un televisor en su cuarto. Cfr. L. Bogart, Nueva York, Ungar, 1956. 
para el niño, la conducta con relación a la televisión es un hábito hogareño tanto de carácter individualista como familiar. En enero de 1998 el 49\% de los padres del municipio madrileño declara ver la televisión siempre o casi siempre con sus hijos, y el $42,1 \%$ declara hacerlo algunas veces. En mayo de 2000 lo asegura el $31 \%$ de los padres, y el 55,2\% dice hacerlo algunas veces (pregunta 8).

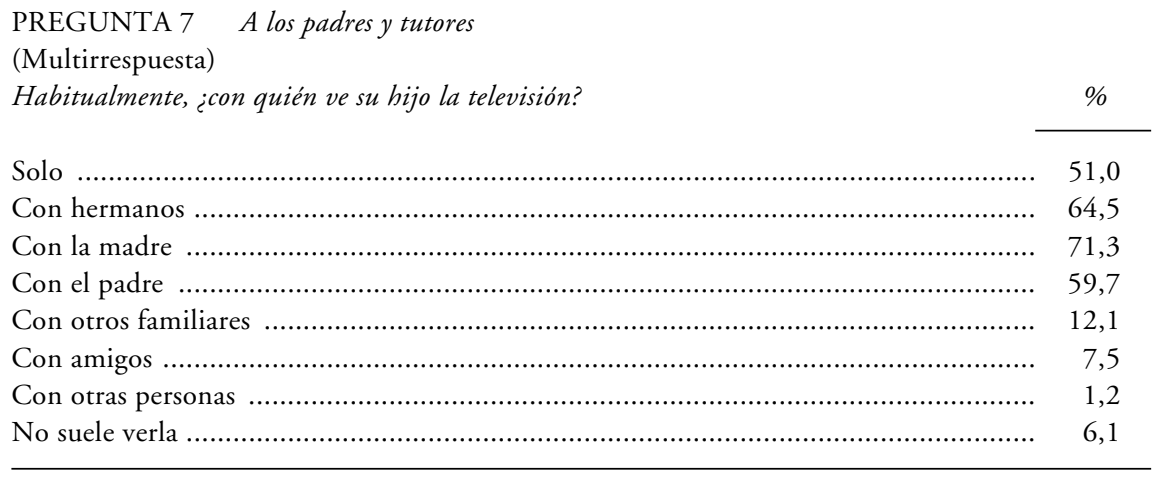

Preguntas a los niños

\section{PREGUNTA 58}

(Multirrespuesta)

¿Con quién sueles ver la televisión por la tarde (hasta las 8,30 o las 9)?

Solo

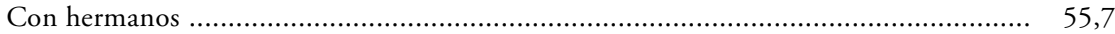

Con la madre ........................................................................................ 51,4

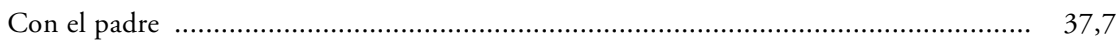

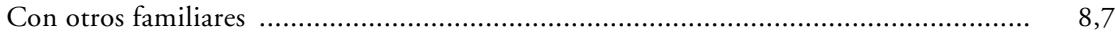

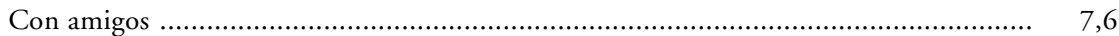

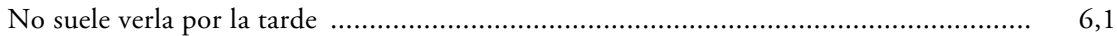

\section{PREGUNTA 59}

(Multirrespuesta)

Y cuando la ves por la noche (después de las 9), ¿con quién sueles verla?

Solo

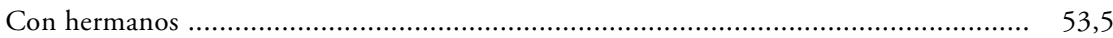

Con la madre …................................................................................... 70,6

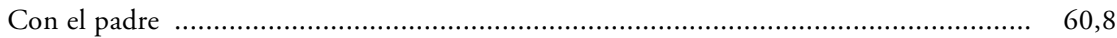

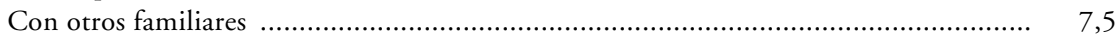

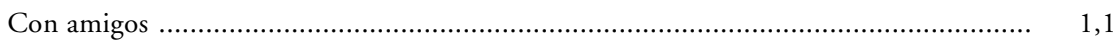

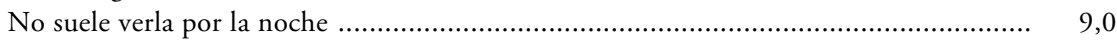


Pero, a la vez, el $40 \%$ de los entrevistados destina un aparato para uso exclusivo de los hijos menores de 16 años. Lo que confirma nuestro anterior comentario de que la televisión se ve, en el hogar, tanto en compañía como en soledad, que el acto de ver la televisión resulta bastante indiferenciado con relación a si contribuye o perjudica el proceso de socialización en el entorno de la vida en familia ${ }^{36}$. En principio, no hay información suficiente para asegurar si favorece el individualismo más de lo que contribuye a promover la vida familiar o si, por potenciar el individualismo en el hogar, tiende a disgregar el entorno comunicativo de la familia. Tal vez pudiera decirse, si se pudiera probar que el hecho de ver la televisión sustituye a la comunicación dialógica entre quienes conjuntamente la ven, que desnaturaliza las posibilidades comunicativas en el seno familiar, pero no hay dato alguno a nuestro alcance que permita validar esa conjetura. Por eso, a nuestro entender, lo que significan los datos de que disponemos no es que la televisión actúe generalizadamente como impulsor del individualismo o como aglutinante o disgregador familiar — según las casos concretos, puede ocurrir una $\mathrm{u}$ otra cosa-, sino que para el niño y, en suma, en el entorno familiar la televisión es un instrumento tan útil y habitual como puede también serlo, por ejemplo, el automóvil, que tiene poco sentido tratar de encontrar en qué medida condiciona o deja de condicionar a la vida hogareña ya que queda integrada como un ingrediente imprescindible de la convivencia cotidiana.

Esa interpretación explica, al menos mejor que cualquier otra, que se produzcan muchas incongruencias en las apreciaciones y manifestaciones del punto de vista de los encuestados. Conectamos ahora con el problema «macluhiano» de los contenidos, es decir, si cabe saltar de la consideración de que el hecho de ver forma parte de la normalidad de la vida del niño a considerar que lo que ve forma parte también del ambiente nómico, que el hecho de ver es el determinante de la relación con la televisión y que lo que se ve es indiferente con respecto al proceso de socialización (empezando por el ámbito familiar) en una sociedad conformada por el medio televisivo. Éste es realmente el problema más de fondo, el de más difícil examen y el de más compleja respuesta. No se espere que resulte de estas consideraciones nada concluyente. Pretendemos tan sólo aprovechar este comentario para ofrecer alguna aportación a partir de la cual se pueda orientar la investigación hacia la consecución de alguna respuesta futura ${ }^{37}$.

Veamos ahora cómo se expresan en el estudio del CIS algunas de estas incongruencias (de naturaleza pragmática) a las que estamos aludiendo ${ }^{38}$. En

${ }^{36}$ Para diversificación de estrategias con relación a este tema, cfr. Callejo, op cit., passim.

${ }^{37}$ En este sentido, este trabajo trata de integrarse en el planteamiento más amplio y ambicioso del proyecto de investigación antes citado.

${ }_{38}$ En el proyecto de investigación enfocamos estos conflictos pragmáticos a través de la teoría de la disonancia cognoscitiva. Cfr. L. Festinger, A Theory of Cognitive Dissonance, Stanford Univ. Press, 1957; versión española del Instituto de Estudios Políticos (Centro de Estudios Constitucionales, Madrid, 1975). Damos por conocidos los términos generales de la teoría, por lo que no descedemos a su exposición. 
efecto, por un lado, los padres se quejan de lo que ven los niños por televisión; por otro, hacen poco por impedir que vean lo que ven; por un lado, reprochan los contenidos vistos; por otro, hacen poco o nada para impedir que los niños los vean. Parece como si el hecho de ver la televisión fuera tan ineluctable que implicara que es inútil poner impedimentos a los niños para que no vean lo que ven aunque a los padres les disguste. Como digo, ésta es una interpretación macluhiana (y, de modo inverso, sartoriana) de los efectos sociales de la televisión.

Vayamos al asunto. En el estudio del CIS realizado en febrero de 1997, el $61 \%$ de los encuestados respondía estar "más bien de acuerdo" con la afirmación de que «los padres son los únicos responsables de evitar que los niños vean programas violentos o que no sean adecuados para ellos»; a la vez aseguraban que el grado de violencia de los programas o películas que se emiten es muy alto $(26,6 \%)$ o más bien alto $(46,3 \%)$; igualmente se decía que la televisión emite muchos (43\%) o bastantes $(45,8 \%)$ contenidos violentos en sus distintos programas. Del mismo modo, el 89,8\% está conforme con que «las distintas cadenas de televisión deberían llegar a un acuerdo entre ellas para emitir menos contenidos violentos en la programación $»^{39}$. El 89,3\% afirma también estar «más bien de acuerdo» con que «en las horas en que los niños suelen ver la televisión, debería impedirse que las televisiones emitieran programas violentos o que no sean adecuados para ellos».

Ahora trataremos de delimitar en qué consiste el conflicto pragmático al que nos hemos referido al delimitar las intenciones de fondo que inspiran este comentario y alientan otros trabajos: si un $61 \%$ de los padres consideran ser «los únicos responsables de evitar que los niños vean programas inadecuados o violentos $»^{40}$, debería esperarse que los niños no vieran la televisión en las horas en que aparecen esos programas. Sin embargo, como se emiten en horas en "que los niños suelen ver la televisión», resulta que es ineluctable que los vean y que la opinión que a los padres merecen los programas pasa a segundo plano

${ }^{39}$ El acuerdo ya existía desde abril de 1993. Antes de que fuera trasladada en octubre la Directiva «Televisión sin Fronteras» a la legislación española, el entonces Ministerio de Educación y Ciencia propuso a las empresas que firmaran un Convenio sobre principios para la autorregulación de las cadenas de televisión en relación con determinados contenidos de su programación referidos a la protección de la infancia y la juventud, que se rubricó por TVE, las cadenas autonómicas y las cadenas privadas, aunque ni se lleva ni nunca se llevó a la práctica.

${ }^{40}$ Obsérvese que la pregunta no se refiere a si los padres tienen responsabilidad compartida con otros que no se indican. Para los encuestadores, parece que se da por presupuesto que la responsabilidad paterna o es exclusiva (61\%) o es compartida (39\%, por exclusión). La segunda pregunta adjudica implícitamente alguna responsabilidad compartida con los padres a las cadenas de televisión. Pero lo que tiene relevancia, pues, es que un $61 \%$ de los encuestados juzgue que la responsabilidad paterna es exclusiva. Sería interesante que esta pregunta se hubiera hecho sólo a los padres o tutores (para eso está la encuesta de mayo de 2000, que es el objeto preferente de nuestra atención). Con respecto a si debería impedirse que las televisiones emitieran programas violentos, la pregunta se expresa en impersonal, de modo que no se indica a quién competiría la iniciativa o la función de impedirlo. 
- a pesar de que admiten que es responsabilidad suya evitarlo- con respecto a la aceptación del criterio de que, en una sociedad conformada por la televisión, el hecho de que los niños vean lo que ven forma parte de convenciones sociales tan arraigadas que no vale la pena esforzarse en cambiarlas.

Este aspecto puede profundizarse al considerar lo que juzgan los padres acerca de si los niños ven mucho o poco la televisión comparando ese juicio con las respuestas acerca del tiempo que efectivamente dedican a verla. Sabemos que, según los padres, el tiempo que los niños dedican a ver la televisión oscila entre una y dos horas $(44,7 \%)$, entre dos y tres horas diarias $(24,1 \%)$ y menos de una hora $(17,9 \%)$, pero lo que los padres juzgan acerca de ese tiempo puede observarse en las siguientes respuestas a la encuesta que comentamos:

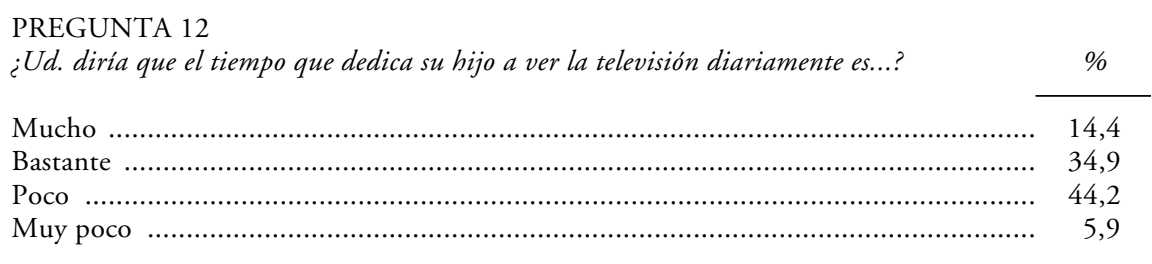

Curiosamente, los padres consideran que es poco el tiempo que dedican a verla, pero les gustaría que dedicaran más tiempo a otras actividades, como se desprende de las respuestas a la siguiente pregunta:

\section{PREGUNTA 10}

¿Y a qué le gustaría a Ud. que dedicase más tiempo (su hijo fuera de las horas de clase $y$ del tiempo que pase estudiando o haciendo deberes)?

Hacer deporte

Jugar (todo tipo de juegos, incluidos juegos de ordenador, videojuegos, etc.) …........... 14,6

Ver la televisión

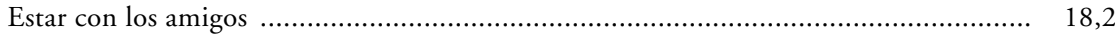

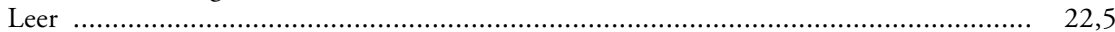

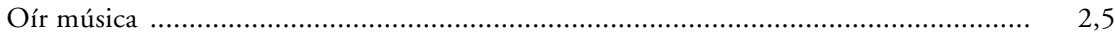

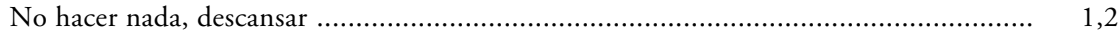

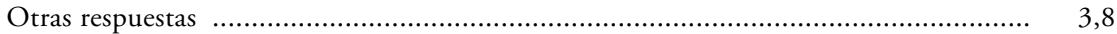

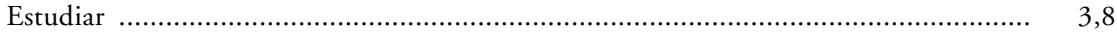

Sería interesante tratar el tema de la lectura, pero el comentario haría excesivamente extenso este artículo. De momento, lo que interesa subrayar es que hay en estas respuestas, aunque más matizada, otra manifestación del conflicto 
pragmático al que nos estamos refiriendo. Que los niños dedican tiempo a ver la televisión es evidente, que los padres piensan que es "poco" parece claro en las respuestas, pero que, a la vez, les parece "demasiado», al menos comparativamente con el tiempo que les gustaría que dedicasen a otras actividades, es también patente, como se desprende de que sólo un 2,1\% afirma que le gustaría que dedicasen más tiempo a ver la televisión, mientras que a un 22,5\% le gustaría que dedicasen más tiempo a la lectura. Qué hace el padre para promover la lectura es asunto distinto de si el padre piensa que es preferible que lean más y vean menos. El conflicto pragmático consiste en que el padre no pone los medios que debería poner para que los niños leyeran más y vieran menos televisión.

Los niños con edades comprendidas entre 4 y 12 años pasan 162 minutos diarios de promedio - es decir, menos de tres horas diarias - frente al televisor, según datos de GECA, que tiene como fuente a Sofres, referidos a la temporada 1999-2000. Parece un consumo importante, pero hay que tener en cuenta que es inferior en 59 minutos —es decir, casi una hora menos- a la media de todos los telespectadores (221 minutos diarios en dicha temporada para el «total individuos»). De hecho, los niños son, junto con los jóvenes con edades comprendidas entre los 13 y los 24 años, los que menos televisión ven. Es más, si se tiene en cuenta que los niños representan el 10,1\% del universo televisivo español (universo de Sofres) y que el público infantil representa únicamente el 7,2\% de la audiencia de la temporada 1999-2000, podría deducirse al correlacionar los dos porcentajes con el consumo de otros segmentos de edades que los niños tienen un interés limitado por la televisión, como se apunta en algunas de las consideraciones provisionales de la citada investigación "Estudio de la oferta y de las preferencias temáticas de la audiencia televisual infantil en España».

En esta investigación en curso se pone de manifiesto que el consumo televisivo infantil está condicionado por variables como los hábitos socioculturales y las obligaciones escolares. De hecho, los niños ven más televisión durante los períodos festivos de Navidad (215 minutos, es decir, 3 horas y 35 minutos, que suponen un incremento del $32,7 \%$ respecto a la temporada) y de Semana Santa (168 minutos, es decir, 2 horas con 48 minutos, que equivalen a un $3,7 \%$ más que el promedio de la temporada). También cabe señalar que entre las conclusiones provisionales de la citada investigación se destaca que los niños modifican más que otros grupos de edad sus hábitos televisivos con la llegada del fin de semana, al menos en dos aspectos: por una parte, aumentan considerablemente su permanencia ante la pantalla, ya que pasan de un consumo de 150 minutos (de lunes a viernes) a 190 minutos en fines de semana (201 minutos en sábado y 180 minutos en domingo); por otra parte, se convierten en protagonistas de bandas horarias, como la mañana (período comprendido entre las 9:00 y las 13:00 horas, en el que las cadenas concentran su oferta de programas infantiles) y la franja conocida como despertador (período de tiempo comprendido entre las 7:30 y las 9:00 horas). Los niños tienen menor presencia que los adultos en todas las franjas horarias excepto en estas dos, en las que el consumo infantil es más elevado que el adulto. No obstante y 
pese al protagonismo de los niños en las mañanas, el público infantil —al igual que el público joven y adulto- consume más televisión en el período principal (conocido como prime time, período de tiempo comprendido entre las 21:00 y las 00:00 horas). El promedio de consumo infantil — de lunes a viernes en la temporada 1999-2000 — asciende a 41 minutos diarios; una parte de ese tramo o franja corresponde a horario de emisiones para adultos. Incluso en horarios más tardíos hay presencia de niños, como sucede entre las 00:00 y las 2:30 — período conocido como late night_, si bien el consumo baja a 7 minutos diarios (frente a los 22 minutos diarios que consumen los adultos).

Otra característica que destaca la mencionada investigación («Estudio de la oferta...») es que el consumo infantil crece proporcionalmente con la edad: los niños de 4 a 6 años pasan 143 minutos diarios frente al televisor, mientras que los niños de 11 a $12^{41}$ años le dedican media hora más. Por clases sociales, los niños de clase baja (208 minutos diarios de promedio) dedican una hora y media diaria más a ver la televisión que los de clase alta (119 minutos diarios de promedio). Por sexos, las niñas incrementan su presencia ante la televisión más rápidamente que los niños, a medida que crecen. Así, las niñas de 11 y 12 años consumen 15 minutos diarios más que los niños. Se trata, por lo demás, de un consumo estable, con bajas oscilaciones: 163 minutos diarios de consumo infantil en la temporada 1995-1996 y 162 minutos en la temporada 1999-2000.

Volvamos ahora al tema de la responsabilidad, al que nos hemos referido al comentar antes la encuesta de 1997. En el estudio de mayo de 2000 las respuestas recogidas se refieren no a la opinión general, sino a la de los padres y tutores. Cabe esperar que las actitudes de los padres con respecto a quien compete la responsabilidad de evitar que los niños vean programas violentos sea más exigente que la opinión no discriminada, y efectivamente es así:

\section{PREGUNTA 18}

¿Cree Ud. que los padres tienen obligación de controlar los programas de televisión que ven sus hijos? ${ }^{42}$

Sí, es una obligación de los padres

${ }^{41}$ Confirman el sentido de estas conclusiones sobre el sentido de la "disonancia pragmática» observaciones que pueden verse en la obra de Callejo: «Se reconoce una contradicción entre lo que señalan como "deber ser" de la televisión y la utilización más o menos habitual — "lo normal”- que hacen del medio. Una contradicción que parece aumentar según se asciende en la estructura social» (pp. 56 y 187).

42 Complementariamente se pregunta al 73,8\%: «¿Hasta qué edad cree Ud. que deben controlar los padres lo que sus hijos ven en la televisión?». La media de años es de 15,41 años, con una desviación típica de 2,11. Otro aspecto que hay que considerar es que el $16,1 \%$ matiza la respuesta anterior con «no conviene exagerar», porque ese matiz confirma lo que el $73 \%$ entiende por «obligación de controlar». 
PREGUNTA 19

¿Y cree Ud. que las distintas cadenas de televisión deben poner programas adecuados

para niños y adolescentes durante las horas en que éstos pueden ver la televisión?

Sí

No

$\mathrm{NC}$

\section{PREGUNTA 19a}

¿Hasta qué hora se les podría pedir a las cadenas de televisión este requisito?

Sólo para un 4,6 más tarde de las 11 .

\section{PREGUNTA 21}

¿Cuál de las siguientes frases se acerca más a su forma de pensar?

Preocuparse por los programas de televisión que ven los niños y adolescentes es una labor exclusiva de los padres ${ }^{43}$

Los padres no pueden estar en todo, y necesitan también el apoyo de los maestros y profesores para enseñar a ver la televisión a sus alumnos

Los verdaderos responsables de lo que ven nuestros hijos en televisión son los programadores de las distintas cadenas

Cosa distinta es que el niño se habitúe a correlacionar su criterio de normalidad con lo que ve por televisión. No se trata de una normalidad simple. Naturalmente que va aprendiendo a la vez a oponer realidad y ficción, pero también se habitúa a considerar normal la expresión de la ficción y lo que su aceptación de lo ficticio supone de contrapartida hacia lo que no lo es. Aunque el tema es importante, no lo abordaremos en este comentario.

${ }^{43}$ Aunque la adhesión a esta pregunta sea inferior a la de la encuesta de 1997, hay que tener en cuenta que en aquélla no se incluía ninguna respuesta complementaria que matizara la pregunta de si los padres son «los únicos responsables», mientras que en ésta se incluyen matices de reparto o de transferencia de la responsabilidad paterna. De todos modos, aunque un 29,5\% considere responsables a los programadores, lo que es un dato que debe tenerse en cuenta, de él no puede colegirse inferencia clara alguna ya que no se matiza si quienes así piensan pertenecen a los que se quejan de la violencia de la programación o a los que no se quejan de ella. Al respecto, en la encuesta se contesta que los programas que ven los hijos «son buenos y entretenidos» $(24,9 \%)$ y "ni buenos ni malos, pero inofensivos» (42,5\%); a veces son perjudiciales y nocivos (29\%). Por otro lado, los programas infantiles dirigidos a los niños menores de 12 años «son beneficiosos para la educación» (14,6\%); son indiferentes, pero adecuados a su edad (35,5\%); a veces pueden ser perjudiciales o nocivos (42\%). Aunque el grado de «nocividad» es bastante alto, la creencia predominante es que la programación es, al menos, inofensiva. Ahora bien, si se trata de niños de 12 años, entonces aumenta significativamente la impresión de nocividad. 


\section{La comodidad}

El rasgo que explica que la difusión sea tan generalizada y su uso tan asiduo es la comodidad. Si definimos "comodidad» en términos económicos, como el ahorro de energía, de esfuerzo, de trabajo o de gasto, para realizar un fin cualquiera, la televisión es cómoda porque ahorra el trabajo de salir del entorno más próximo, no modifica nuestra vida habitual, se adapta a ella, convierte sin gasto lo más lejano en mundo cercano, nos lo muestra desde el reducto cotidiano sin necesidad de tener que salir del domicilio o del lugar ${ }^{44}$. Para verla no sólo no hace falta hacer esfuerzo alguno, sino que suprimimos el esfuerzo que habría que hacer si hubiéramos de ver directamente lo que vemos a través de la pantalla. Nos permite estar pasivamente presentes en los sitios más distantes. Naturalmente, ese ahorro no deja de entrañar alguna limitación (es decir, hay que pagar por él algún tipo de precio) ${ }^{45}$. La supresión del esfuerzo físico unifica la diversidad de actividades, las hace homogéneas ${ }^{46}$. No es lo mismo ir al teatro que verlo por televisión, ni ir al estadio que ver las olimpiadas por televisión. Ver cine, teatro, olimpiadas, recitales, son actividades distintas. Al verlos a través de la televisión transformamos esa pluralidad de iniciativas en una misma, reiterada, homogénea y uniforme actividad. Algunos consideran que ver la televisión no es una actividad, por más que los sociólogos la consideran hegemónica entre las que implican exposición de los ciudadanos a los medios. Algunos utilizan la palabra "pasividad» para referirse al hecho de verla; podría recurrirse al oxímoron: es una actividad pasiva. Incluso puede insistirse más en esta idea. Está muy bien dicho eso de "ver la televisión» porque, en efecto, primero y principalmente, se ve la televisión y, luego y secundariamente, se ve algo a través de ella ${ }^{47}$. También hay que matizar que en el futuro las tecnologías favorecerán el uso interactivo - y quizás participativo- del medio y, por tanto, otro tipo de relación o «actividad».

Volvamos al conflicto pragmático. Esta apreciación, creemos, arroja bastante

${ }^{44}$ El planteamiento macluhiano de los efectos sociales de los medios y de su teoría sobre «el medio como mensaje» se basa en esta hipótesis directamente aprendida en la lectura de los economistas, y muy en concreto de Adam Smith. La hipótesis explica también por qué, desde el punto de vista macluhiano, la televisión como medio de comunicación social es ineluctable. En efecto, según McLuhan, la extensión de un sentido se convierte en un fenómeno socialmente ineluctable cuando proporciona un abaratamiento de la energía social necesaria que habría que emplear para alcanzar fines comunes ineluctables. Por ejemplo, eso explica que, una vez que aparece la rueda, cualquier cultura que acceda a comprender qué ventajas proporciona, es decir, que el esfuerzo de construirla lleva aparejado un ahorro del esfuerzo colectivo que habría que emplear para alcanzar los mismo fines que usando la rueda se pueden alcanzar, ninguna cultura, una vez comprendido el significado en términos de economía de lo que significa la incorporación de la tecnología de la rueda, se resistirá a utilizarla. Lo mismo cabe decir de la televisión: como extensión del sentido común o del tacto implica un ahorro global de la energía social comunicativa.

${ }_{45}$ Cfr. McLuhan.

46 McLuhan insiste, no menos que Sartori, en la idea de homogeneidad, bien entendido que, a su juicio, su origen está en la imprenta más que en la televisión.

${ }^{47}$ Lo que no es más que un modo empírico de expresar la tesis de McLuhan (el medio es el mensaje) y de Sartori. Esta prelación del hecho de ver sobre el qué se ve fue anticipada ya por el estudio de Callejo ya citado 
luz sobre el hecho de que los padres, a pesar de que dicen que les preocupa lo que sus hijos ven por televisión, no se ocupen de que no lo vean tanto como cupiera deducir si fueran consecuentes con sus declaraciones: tal vez consideran, «macluhiana» y no conscientemente, que lo que, a fin de cuentas, tiene (sartorianamente) importancia es el hecho socialmente ineluctable de que sus hijos ven la televisión y que el ver la televisión significa participar en un modo culturalmente homogéneo de mirar y percibir ${ }^{48}$, un estilo culturalmente homogéneo de prolongar y compartir socialmente la capacidad sensorial socializada de tal eficacia comunicativa que, con relación a ese efecto homogeneizador socialmente primario, lo que se vea o deje de ver sólo tiene un valor secundario ${ }^{49}$. Veamos ahora, a través de los datos recogidos por los estudios que estamos comentando, en especial el de mayo de 2000, los rasgos o hábitos que pueden interpretarse en términos de las ideas macluhiana y sartoriana de que el ver la televisión homogeneiza, uniformiza, unifica el modo cultural de ver de la sociedad independientemente de quése vea por ella.

La encuesta del CIS de enero de 1998 sobre «Hábitos de comportamiento ante la televisión» en el municipio de Madrid ofrecía, entre otros muchos datos, las siguientes respuestas a la pregunta sobre la actitud del espectador a la hora de encender el televisor para verlo:

Estudio 2272, enero de 1998

\begin{tabular}{ccc}
$\begin{array}{c}\text { Habitual } \\
(\%)\end{array}$ & $\begin{array}{c}\text { Aveces } \\
(\%)\end{array}$ & $\begin{array}{c}\text { Nunca } \\
(\%)\end{array}$ \\
\hline
\end{tabular}

En su casa se selecciona el programa que se va a ver antes de encender la televisión

34,2

40,3

En su casa se enciende la televisión y según lo que haya se elige un programa u otro

En su casa se enciende la televisión por costumbre aunque no se esté pendiente de ella

48 «De aquí a pocos decenios será posible descubrir la revolución en la percepción y en la motivación humanas que se producirá como consecuencia de la contemplación de la nueva red en mosaico que es la imagen televisiva». La galaxia, p. 385.

${ }^{49}$ McLuhan, como Sartori, alude con frecuencia a la influencia de la televisión (producto técnico-mecánico característico de la cultura occidental) sobre culturas no occidentales. La actitud macluhiana es equívoca: la televisión acaba imponiéndose como modo de ver homogéneo, como extensión tecnológica del sentido que remite a una percepción uniforme. Siendo la tecnología una aportación de Occidente, cabría pensar que la difusión del modo televisivo de percibir entrañaría la «occidentalización», pero, en lugar de eso, insiste en afirmar que la mutación del proceso de occidentalización aportado por la electricidad que conduce a la globalización implica, a su vez, la aldealización tribal. «Los mismos occidentales se están desoccidentalizando en virtud de la actual aceleración eléctrica» (p. 110). Puede que tenga razón y que la "aldea global», al ser una «aldea multicultural», acabe devorando lo que se consideró tradición occidental. En todo caso, no cabe duda de que en esto como en tantas otras cosas se adelantó a definir un problema, el de la invasión de Occidente por el multiculturalismo como consecuencia de las migraciones, movimiento que en parte es dependiente de la imagen de Occidente que proyectan los medios de comunicación. 
Estos datos permiten postular una diferencia importante entre ver la televisión y cualquier otra forma de ocio, una diferencia que tiene que ver con la comodidad, ese tercer rasgo que estamos comentando. Hablando con propiedad, la tendencia predominante no consiste en ir a ver algo por la televisión, sino en encenderla y mirar o no lo que se ve en ella.

Resulta significativo que la diferencia entre la adhesión a la emisora de radio y a la cadena de televisión sea, a este respecto, muy acusada. La encuesta de 1997 proporciona las siguientes diferencias con relación a los hábitos de las audiencias de radio y de televisión:

Estudio 2238, febrero de 1997

No me gusta cambiar de una cadena a otra

Normalmente cambio de una cadena a otra
No me gusta cambiar de una emisora a otra. Casi siempre escucho la misma emisora de radio

Normalmente cambio de emisora a otra hasta que encuentro algún programa que me gusta
(\%)

$(\%)$ 66,9 32,5

Las selecciones de radio, de la televisión llamada "generalista» e Internet son directamente comparables pues coinciden en que no entrañan ningún coste físico (no hay que salir del entorno) ni económico (excepto el de la conexión eléctrica) por el hecho de optar entre una u otra de las posibilidades disponibles. No ocurre así con otros medios de comunicación social o de entretenimiento, como el periódico, los libros, etc. En estos casos no hay posibilidad de cambio sin costo. Por esta razón, cabe presumir que la comparación de las actitudes sobre selección de cadenas y emisoras sea muy indicativa. Pero la capacidad de la radio como sustituto virtual de acontecimientos sociales es mucho más escasa que la de la televisión. Cuando se va a ver algo movido por un interés específico, la televisión actúa entonces como sustituto virtual de lo que realmente interesa, como un intermediario que suministra la sensación plena de estar presente en un acontecimiento sin estarlo. En esas condiciones, la diferencia entre estar real o físicamente presente o no estarlo se reduce de modo tan significativo que el ahorro de energía que supone estar pendiente de la pantalla sin tener que moverse de un entorno próximo o familiar, con relación al gasto dinerario y al esfuerzo físico que supone estar presente para participar material o directamente en el lugar donde se producen los hechos, resulta, en la economía del esfuerzo con relación al logro de fines o gratificaciones, muy compensatorio ${ }^{50}$.

La actividad de ir a ver algo requiere alguna iniciativa por parte de quien se decide a ir a verlo. La experiencia de que efectivamente se participa en un

${ }^{50}$ Las televisiones suelen pagar a los asistentes para asegurar que los auditorios de los programas que se realizan ante el público estén repletos. 
espectáculo compensa el esfuerzo que hay que realizar para conseguir participar: salir del propio ambiente o del entorno habitual para ir a un ambiente específico, al lugar que se desea visitar o concurrir. Se trata de actividades que requieren esfuerzo, es decir, son formas costosas de participación. No sólo hay que decidir, ya que, además, hay que actuar, moverse, prescindir de lo acostumbrado, cambiar de entorno. Esta actividad queda reducida al mínimo cuando el espectador se limita a mirar a través de la pantalla. Pero la sensación de participación no se reduce en la misma proporción. Lo que se pierde en participación lo compensa con creces esa ilusión que ofrece la pantalla al suministrar todas las sensaciones necesarias como para producir la apariencia de que se participa plenamente sin necesidad de realizar esfuerzo alguno. Más que una forma activa de ocio, se trata, como muy bien dicen ahora, de una participación virtual: el espectador no está física o directamente presente en el lugar de la representación pero obtiene, aunque sea en apariencia, las mismas sensaciones que obtendría si participara directamente del acontecimiento transmitido.

\section{Conclusión sobre el conflicto pragmático}

Independientemente de estos aspectos que reflejan el modo como la televisión forma parte de los procesos espontáneos mediante los que nos habituamos a contrastar realidad e ilusión y del sistema de gratificaciones a que no menos espontáneamente se adapta el niño, se puede hacer alguna referencia complementaria final. Creemos que la observación que vamos a exponer es especialmente significativa a partir de los datos de la última encuesta que comentamos. Se trata de contrastar entre los criterios normativos que los padres expresan acerca de cómo deben controlar lo que ven sus hijos y sus ideas acerca de lo que no conviene que vean y la conducta efectiva, es decir, cómo de hecho los atienden y lo que, como consecuencia de la atención que les dedican, los niños ven o dejan de ver. Ésta es la principal manifestación del conflicto pragmático entre criterios de los responsables y su conducta como responsable. Que haya disonancia entre criterio y conducta es algo normal. Justamente por eso, las normas no se cumplen siempre. Casi todo el mundo aceptaría que la observancia de las reglas de tráfico es una obligación exigible a todo ciudadano que conduzca un vehículo, pero de eso no se deduce que las señales de tráfico se cumplan mejor. Pero no se refiere esta observación sólo a las normas impuestas, como las de tráfico o las tributarias. Tampoco las ideas normativas (privadas) de las personas coinciden con sus comportamientos efectivos. Se puede considerar que conducir a demasiada velocidad o tras haber bebido algunas copas es temerario y, no obstante, muchos de quienes lo consideran así contradicen con su praxis su propia consideración. Se manifiesta, por decirlo de este modo, una disonancia de tipo pragmático que puede asociarse a la diferencia que se puede establecer entre proponer o aceptar una norma de conducta y aplicarla. Pues bien, en el caso de la televisión, esa disonancia ha sido 
observada con frecuencia pero interpretada de forma muy superficial, como si se tratara de un asunto de hipocresía social o algo similar. Si las conductas efectivas coincidieran con los gustos expresados, los programas informativos, documentales y de divulgación científica o artística tendrían más audiencia que los de entretenimiento ${ }^{51}$.

En la encuesta de enero de 1998, el 46\% de los encuestados declara que el tipo de programa que le resulta más interesante son las «noticias o telediarios», y el 39,6\% asegura que es a los que «dedica más tiempo en primer lugar». Sólo el 3,5\% declara «muy interesante en primer lugar» los "concursos y programas cara a público», y un $3,1 \%$ dice que le "dedica más tiempo en primer lugar». El 16,3\% asegura que los "documentales» son "más interesantes en primer lugar» y el 9,3\% que les «dedica más tiempo en primer lugar», mientras que las «emisiones deportivas» son las «más interesantes en primer lugar» para el 3,3\% y el 6,3\% les «dedica más tiempo en primer lugar». En la encuesta de mayo los programas más vistos con más frecuencia son "películas» $(68,2 \%)$, «informativos, documentales» $(58,1 \%)$, «series, telecomedias, novelas» $(34,3 \%)$. Si se comparan las declaraciones con las mediciones de audiometría elaboradas por institutos como GECA se puede comprobar que hay disonancia entre lo que se dice y lo que se hace. De hecho, el programa más visto durante la temporada 1999-2000 fue Gran Hermano, un producto híbrido de realismo (reality, según la expresión estadounidense) y concurso. También en las listas de las emisiones más vistas suele aparecer el fútbol con mucha más frecuencia y con mayores índices de audiencia que el cine, mientras que las series y la ficción, especialmente las de producción española, encabezaron las listas de la temporada 1999-2000, si bien su consumo disminuyó en la temporada siguiente ${ }^{52}$.

¿Qué es lo que manifiesta esta distinción entre declaraciones y conducta. En primer lugar hay un contraste entre lo que se considera "más interesante» (el juicio de valor) y lo que se declara ver. En segundo lugar hay una diferencia entre lo que se declara ver y lo que las mediciones audimétricas indican que en la práctica se $\mathrm{ve}^{53}$. ¿Cómo se explica esa contraposición? Hay muchas formas de interpretarla. Lo más habitual es considerar que el encuestado es hipócrita. Pero esa hipocresía es significativa de una diferencia más importante. La que separa criterio y conducta. Trataremos de esta cuestión. ¿Qué es lo que se declara ver? Evidentemente, no se declara ver lo que de hecho se ve. Se declara ver lo que uno considera que es socialmente más correcto decir que se ve. La tendencia muestra que no se declara tanto la conducta efectiva como una rectificación de ésta por aplicación de un criterio de corrección social. Es esa recti-

51 En su estudio sobre la actividad de la audiencia, Callejo ya advirtió con claridad esa contradicción. "Se reconoce una contradicción entre lo que señalan como "deber ser" de la televisión y la utilización más o menos habitual — "lo normal" - que hacen del medio. Una contradicción que parece aumentar según se asciende en la estructura social». Op. cit., p. 56 . Véanse también pp. 187 y 189.

52 Cfr. GECA, El Anuario de la Televisión 2001, Madrid, GECA, 1990, pp. 12-13.

53 En el estudio 2238 se ofrece la siguiente respuesta (en porcentajes): 
ficación a lo que se suele llamar "hipocresía» del encuestado. Pero esa hipocresía, como digo, es indicio de que el encuestado tiene conciencia de la diferencia entre lo que es un juicio de valor y una conducta. Esta distinción merece más atención de la que suele ser objeto porque su consideración puede servir de base empírica para contraponer los criterios de cuantificación y de cualificación de las audiencias. Basándose en la audiometría, los programadores tienden a identificar la calidad de los programas con su aceptación. Como el negocio de la televisión gratuita consiste en vender audiencias a la publicidad, la rentabilidad comercial se funda en la cuantificación de la audiencia, y la eficacia o el éxito de un programa depende igualmente de ese criterio. Para pasar a considerar desde ahí a la cantidad como fundamento de un juicio de valor de calidad no hay que dar paso alguno. La audiencia ve lo que quiere libremente $y$, porque le gusta, prefiere verlo a no verlo. Y el argumento es difícilmente rebatible. Incluso puede pasarse a considerar que, por tratarse de una elección, la aceptación mayoritaria de un programa por la audiencia cuando ha podido optar entre varios es una manifestación democrática del gusto comparable a una decisión electoral.

Es difícil separar el éxito de la aceptación. Se dice que una obra de teatro o una película han tenido éxito si duran en la cartelera. Tanto más tiempo de permanencia, mayor el éxito. La equiparación es sencilla e inmediata: tanta más amplia la audiencia durante más tiempo, tanto mayor el éxito de un programa. Tantas más ediciones, mayor éxito editorial. Sin embargo, las equiva-

\begin{tabular}{|c|c|c|c|c|c|}
\hline $\begin{array}{c}\text { Tipos de programa que ve } \\
\text { en televisión }\end{array}$ & $\begin{array}{l}\text { Habitual- } \\
\text { mente }\end{array}$ & $\begin{array}{l}\text { Con cierta } \\
\text { frecuencia }\end{array}$ & $\begin{array}{l}\text { De vez } \\
\text { en cuando }\end{array}$ & $\begin{array}{c}\text { Casi } \\
\text { nunca }\end{array}$ & $N C$ \\
\hline Telediario/informativos & 69,4 & 15,4 & 9,9 & 5,3 & \\
\hline $\begin{array}{l}\text { Culturales/divulgativos/documen- } \\
\text { tales }\end{array}$ & 21,1 & 24,8 & 32,0 & 22,0 & \\
\hline Series & 11,7 & 13,4 & 25,1 & 49,7 & \\
\hline 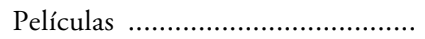 & 27,4 & 25,8 & 31,6 & 15,1 & \\
\hline Espectáculos/musicales/magacines.. & 12,1 & 18,1 & 30,4 & 39,4 & \\
\hline 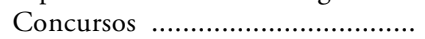 & 10,1 & 16,6 & 27,6 & 46,6 & \\
\hline Debates/entrevistas ........................... & 12,2 & 23,1 & 31,7 & 32,9 & \\
\hline 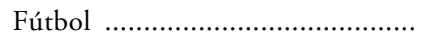 & 25,7 & 12,3 & 14,3 & 46,6 & \\
\hline 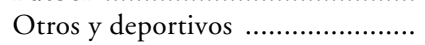 & 16,2 & 12,5 & 19,4 & 51,7 & \\
\hline
\end{tabular}

Sin embargo, el orden de preferencias —o, mejor, de los programas más vistos del conjunto de las cadenas durante la temporada 1999-2000, excluidas las retransmisiones deportivas y las películas de cine - fue, por géneros de programas, el siguiente, según los datos del citado Anuario de GECA: el ya mencionado espectáculo documental Gran Hermano, series de ficción, programas de humor, concursos, un informativo (¡el Telediario del fin de semana de TVE!, que aparece en el lugar $21 .^{\circ}$ de una relación de los 50 programas más vistos), magacines de crónica rosa y de sucesos, y seriales (culebrones). Debemos precisar que no es posible establecer una comparación precisa entre los resultados de la encuesta y los índices de audiencia que elabora Sofres porque estudian aspectos diferentes y con metodologías distintas. 
lencias pueden ocultar simplificaciones. Aunque dependientes, la relación entre cantidad de espectadores y calidad del espectáculo no es directa. Un partido de fútbol puede generar una gran expectación y luego resultar aburrido o decepcionante. Sin embargo, adoptar una conducta ante el televisor y expresar un criterio político o un gusto estético son cosas distintas. Una papeleta electoral sintetiza un conjunto de valores emotivos, intelectuales y de expectativas o creencias acerca de lo que puede ser más conveniente para la comunidad, pero es independiente de la conducta particular que, sobre esos juicios, valores y sentimientos, adoptará el individuo que la deposite en la urna. Alguien puede considerar que es preferible que aumenten los impuestos y vote por ello, pero eso no garantiza que si no hubiera inspección contribuyera libremente al erario. No hay inspección que obligue a las audiencias de televisión a aplicar sus propios criterios normativos sobre el gusto de la programación. Lo que dicen que piensan o prefieren los telespectadores es distinto de lo que hacen. Es decir, las decisiones que mide el audímetro no se refieren a criterios normativos estéticos o morales, no reflejan gustos o preferencias culturales, sino conductas, y, del mismo modo que cualquier tipo de conducta, la del telespectador puede expresar la transgresión de los propios criterios. De hecho, los padres no ven mucho la televisión con sus hijos, pero afirman en gran proporción que si ven con ellos algún programa que consideran inadecuado su reacción es cambiar de programa si no consiguen convencerlos. Casi las tres cuartas partes de los padres consideran que es una obligación suya controlar los programas que ven sus hijos, pero no llegan a la mitad los que comentan habitualmente con sus hijos los programas que ven. Si más del $40 \%$ de los niños tiene a su disposición un televisor, la posibilidad de que sean efectivamente controlados por los padres que declaran que es obligación suya controlarlos resulta más que dudosa. Ni tampoco los niños ven los programas porque les gusten. Los niños los ven porque se adaptaron a la televisión como se adaptan a la cuna o a la hora en que ha de tomarse el desayuno. Ven lo que les ponen. Y por qué ven los padres y los telespectadores lo que ven, aunque no presuman muchas veces de verlo o presumen que ven otros programas distintos de los que realmente ven, remite a motivos de difícil conocimiento.

Es un aspecto, entre otros, en que la última encuesta del CIS permite distinguir entre criterio y conducta. Hay otros más concluyentes todavía. Sólo nos referiremos a alguno. Por ejemplo, el $86 \%$ de los padres consideran que «los niños adquieren muchas veces malos hábitos porque los ven en televisión», lo que no impide que el $70 \%$ de los niños encuestados aseguren que «ven la televisión el tiempo que quieren", y que sólo un $6 \%$ que si no la ve cuando quiere es "porque en casa sólo me dejan ver algunos programas». Lo que nuevamente se observa, pues, es una inconsecuencia entre criterio y conducta, lo cual no es sino un caso particular de la regla general que distingue entre el criterio normativo de las personas y cómo las personas aplican o viven sus criterios. No es un asunto menor, pues su consideración puede variar algunas ideas rígidas y prejuicios que, sobre el sentido de las audiencias, suelen compartir 
programadores, empresarios, publicitarios y guionistas. Merece ser objeto de reflexión y de comentario. En resumen, los audímetros miden conductas o reacciones de las motivaciones o incitaciones a que son sometidas por los programadores y guionistas. Pero la afirmación de que de esta manera se obtiene información pertinente sobre criterios y gustos estéticos, y la creencia de que puesto que la audiencia reacciona de cierta manera ante determinados estímulos los contenidos que los expresan reflejan preferencias y gustos de la audiencia, son infundamentadas. Éste es un asunto que merece una investigación empírica más seria y provista de un instrumental analítico más complejo del que se suelen servir las interesadas simplificaciones de quienes aceptan las mediciones de la audimetría como resultado de la libre interacción de gustos y preferencias estéticas, normativas o morales de los telespectadores. Con objeto de contribuir a esa investigación, los firmantes de este comentario realizan el proyecto de investigación al que se ha aludido en estas líneas.

\section{ABSTRACT}

This article is based on the comment of several surveys carried out by the Centro de Investigaciones Sociológicas on television-viewing habits, particularly the one carried out in May 2000 on "Television and children: habits and conduct", which consisted of one thousand eight hundred interviews. This survey includes important information on the actual conduct of the children and on the relationship between the parents (or guardians, as the case may be) and their young and adolescent children when it comes to television. The comment does not focus on researching audience activity in relation to television-viewing consumption, as this work has already been done under the sponsorship of the CIS, but aims at drawing up some hypotheses on the meaning of certain relevant statistical data. 